\title{
ПРОГНОЗИРОВАНИЕ БИОДЕГРАДАЦИИ ТЯЖЕЛОЙ НЕФТИ АССОЦИАЦИЕЙ АБОРИГЕННЫХ НЕФТЕДЕСТРУКТИРУЮЩИХ МИКРООРГАНИЗМОВ
}

\author{
Сафаров Альберт Хамитович', \\ Alsaf1978@mail.ru
}

Водопьянов Владимир Васильевич², Vodop@yandex.ru

Ягафарова Гузель Габдулловна', Kafedra_ecologia@mail.ru

Дусаева Яна Маратовна², anadusaeva@mail.ru

\author{
Акчурина Лилия Рамилевна', \\ Akchurina Ir@mail.ru \\ 1 Уфимский государственный нефтяной технический университет, \\ Россия, 450044, г. Уфа, ул. Космонавтов, 1. \\ 2 Уфимский государственный авиационный технический университет, \\ Россия, 450008, г. Уфа, ул. Карла Маркса, 12
}

Актуальность исследования обусловлена необходимостью мониторинга и прогнозирования изменений, происходящих в нефтезагрязненном грунте, в частности, интенсивности процесса биотрансформации нефти и нефтепродуктов, а также изменения количества органотрофных микроорганизмов во времени. Данные, полученные в результате моделирования процессов в системе почва-нефть-микроорганизмы позволят повысить эффективность очистки нефтезагрязненного грунта и тем самым оздоровить окружающую природную среду.

Целью исследования являлось создание математической модели, воспроизводящей процесс деструкции компонентов тяжелой нефти ассоциацией аборигенных нефтедеструктирующих микроорганизмов.

Объектом исследования выступал грунт, загрязненный тяжелой нефтью Нижне-Кармальского месторождения (Республика Татарстан), а также ассоциация аборигенных нефтедеструктирующих микроорганизмов.

Методы. В качестве базы для моделирования была рассмотрена модифицированная модель Келлера-Сигала, которая учитывала также процессы диффузии нефтепродуктов и хемотаксис микроорганизмов. Система уравнений решалась численно, для чего была написана программа на языке Python. Численное решение осуществлялось методом предиктор-корректор.

Результаты. Проведенная работа состояла из двух этапов - экспериментального и расчетного. В ходе первого этапа работы было произведено исследование процесса биодеструкции нефти и нефтепродуктов консорциумом аборигенных нефтедеструктирующих микроорганизмов. На основании полученных результатов была сформирована база экспериментальных данных. На втором этапе по ранее полученным данным было осуществлено построение математической модели, описывающей процесс биодеградации тяжелой нефти и изменение численности нефтедеструктирующих микрорганизмов в нефтезагрязненном грунте. Проведенные вычисления показали достаточно высокую согласованность расчетных данных с экспериментальными. Полученная модель позволит уже на ранних этапах очистки спрогнозировать мероприятия по экологически безопасным способам очистки нефтезагрязненных грунтов.

\section{Ключевые слова:}

Тяжелая нефть, биодеструкция, нефтезагрязненный грунт,

аборигенные нефтедеструктирующие микроорганизмы, математическая модель.

\section{Введение}

Нефтепромышленный комплекс является основным источником техногенного загрязнения природных биоценозов продуктами добычи и переработки нефти [1]. Одним из перспективных направлений рекультивации техногенно нарушенных земель является совместное применение агротехнических и биотехнологических мероприятий $[2-5]$.

Исследования, проведенные по данной тематике, показали, что высокой степени очистки нефтезагрязненных грунтов, в том числе грунтов, загрязненных высоковязкой нефтью, за достаточно короткое время можно достичь при использовании ассоциации аборигенных нефтедеструктирующих микроорганизмов (AHM) $[1,6]$.

Экспериментально установлено, что эффективность процесса биорекультивации техногенно загрязненных земель определяется множеством факторов [7], в частности начальным содержанием нефти и нефтепродуктов, физико-химическими показателями грунта, микробиологическим составом, а также численностью микроорганизмов в самом грунте, наличием фитомелиорантов и т. д. [5, 8-11], в связи с этим достаточно интересным является прогнозирование процесса биодеграда- 
ции нефтяных загрязнений с помощью математической модели.

Целью выполненного объема работ являлось создание математической модели, воспроизводящей процесс деструкции компонентов тяжелой нефти ассоциацией АНМ.

\section{Наработка базы экспериментальных данных}

Для создания моделей, которые описывали бы микробиологические изменения, происходящие в грунтах, загрязненных нефтью, нужны данные, основывающиеся на экспериментальных исследованиях [12-15].

$\mathrm{C}$ целью наработки необходимого объема экспериментальных данных была заложена серия опытов. Работу проводили с использованием модельных образцов нефтезагрязненного грунта, где в качестве полютанта использовали тяжелую нефть Нижне-Кармальского месторождения (Республика Татарстан). Характеристики нефти: плотность

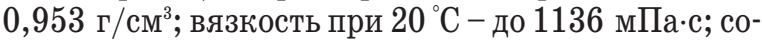
держание ароматических и поли ароматических соединений 46,4 \% мас.; содержание асфальтосмолистых веществ 15,2 \% масс. Внесение нефти в почво-грунт производили из расчета 10 г/кг почвы. В опытах использовали серую лесную почву. Нефтезагрязненный грунт укладывали в специальные емкости $(40 \times 50 \times 30 \mathrm{~cm})$, толщина почвенного слоя в которых составляла 30 см. Суспензию АНМ с титром клеток $10^{8}$ кл/мл добавляли в почвогрунт из расчета $4 \%$ об. (2,96\% мас.). Контрольными образцами выступали чашки без добавления микробных культур. Эффективность процесса биодеструкции оценивали по изменению концентрации нефти и продуктов ее биотрансформации, остаточное содержание которых измеряли методом ИК-спектрометрии, после экстракции четыреххлористым углеродом [16]. Косвенно интенсивность процесса биодеградации определяли по приросту количества органотрофных микробных клеток [17]. Эксперимент проводили на протяжении 18 месяцев, отбор проб производили в первые 50 дней каждые 10 суток, последующие дни каждые 25 суток. С целью исключения ошибок исследования проводили в 5 повторностях, полученные данные усредняли.

Результаты экспериментальных исследований представлены в таблице и на рис. $1,2$.

В результате проведенной работы было установлено, что уже через 12 месяцев после внесения АНОМ содержание нефти и продуктов ее биотрансформации в нефтезагрязненном грунте снизилось в 5,5 раз. А по пришествию 18 месяцев содержание остаточных нефтепродуктов в почве, загрязненной тяжелой нефтью, достигло допустимого уровня.

При этом также отмечено снижение количества органотрофных микроорганизмов в первые 100 суток на 3 порядка, что, возможно, связанно с адаптационным периодом. В последующий период про- исходит восстановление микробиоценоза почвы. На конец эксперимента численность микробных клеток составила $3 \cdot 10^{8}$ кл./г почвы.

таблища. Степень биотрансформащии тяжелой нефти Нижне-Кармальского месторождения

Table. Degree of biodegradation of heavy oil from the NizhneKarmalskoye field

\begin{tabular}{|c|c|c|c|c|}
\hline \multirow[b]{2}{*}{ 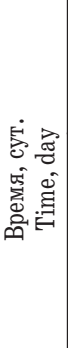 } & \multicolumn{2}{|c|}{$\begin{array}{c}\text { Количество органотрофных } \\
\text { микроорганизмов, кл/г почвы } \\
\text { Number of organotrophic } \\
\text { microorganisms, cells/g of soil }\end{array}$} & \multicolumn{2}{|c|}{$\begin{array}{c}\text { Степень биодеструкции } \\
\text { нефти, \% } \\
\text { Degree of biodegradation, } \%\end{array}$} \\
\hline & $\begin{array}{c}\text { контроль } \\
\text { control }\end{array}$ & $\begin{array}{c}\text { с внесением } \\
\text { AHМО } \\
\text { with aboriginal } \\
\text { petrodestructive } \\
\text { microorganisms } \\
\text { (APM) }\end{array}$ & $\begin{array}{c}\text { контроль } \\
\text { control }\end{array}$ & $\begin{array}{c}\text { с внесением } \\
\text { AHM0 } \\
\text { with aboriginal } \\
\text { petrodestructive } \\
\text { microorganisms } \\
\text { (APM) }\end{array}$ \\
\hline 0 & $(1 \pm 0,1) \cdot 10^{8}$ & $(1 \pm 0,1) \cdot 10^{9}$ & 0 & 0 \\
\hline 10 & $(9 \pm 0,3) \cdot 10^{7}$ & $(9 \pm 0,3) \cdot 10^{8}$ & 0 & 0 \\
\hline 20 & $(8,5 \pm 0,1) \cdot 10^{7}$ & $(8,5 \pm 0,1) \cdot 10^{8}$ & 0 & 0,2 \\
\hline 30 & $(5 \pm 0,2) \cdot 10^{6}$ & $(5 \pm 0,1) \cdot 10^{7}$ & 0 & 0,5 \\
\hline 40 & $(8 \pm 0,1) \cdot 10^{3}$ & $(1 \pm 0,2) \cdot 10^{6}$ & 0 & 1,5 \\
\hline 50 & $(1 \pm 0,3) \cdot 10^{3}$ & $(9 \pm 0,2) \cdot 10^{5}$ & 0 & 2 \\
\hline 75 & $(3 \pm 0,2) \cdot 10^{2}$ & $(7 \pm 0,1) \cdot 10^{5}$ & 1 & 9 \\
\hline 100 & $(1 \pm 0,2) \cdot 10^{2}$ & $(8,5 \pm 0,1) \cdot 10^{5}$ & 2 & 18,5 \\
\hline 125 & $(1 \pm 0,1) \cdot 10^{2}$ & $(1 \pm 0,2) \cdot 10^{6}$ & 3,5 & 27,75 \\
\hline 150 & $(1 \pm 0,2) \cdot 10^{2}$ & $(4 \pm 0,1) \cdot 10^{6}$ & 5 & 37 \\
\hline 175 & $(1,5 \pm 0,3) \cdot 10^{2}$ & $(5,5 \pm 0,2) \cdot 10^{6}$ & 8 & 44,5 \\
\hline 200 & $(2 \pm 0,1) \cdot 10^{2}$ & $(8 \pm 0,2) \cdot 10^{6}$ & 11 & 52 \\
\hline 225 & $(2,5 \pm 0,2) \cdot 10^{2}$ & $(1 \pm 0,1) \cdot 10^{7}$ & 14,25 & 57,25 \\
\hline 250 & $(4 \pm 0,3) \cdot 10^{2}$ & $(3 \pm 0,1) \cdot 10^{7}$ & 17,5 & 62,5 \\
\hline 275 & $(6 \pm 0,1) \cdot 10^{2}$ & $(5 \pm 0,2) \cdot 10^{7}$ & 22,5 & 67 \\
\hline 300 & $(8 \pm 0,2) \cdot 10^{2}$ & $(7 \pm 0,1) \cdot 10^{7}$ & 27,5 & 71,5 \\
\hline 325 & $(2 \pm 0,3) \cdot 10^{3}$ & $(8 \pm 0,3) \cdot 10^{7}$ & 33 & 74,8 \\
\hline 350 & $(7 \pm 0,1) \cdot 10^{3}$ & $(1 \pm 0,1) \cdot 10^{8}$ & 38,5 & 78 \\
\hline 375 & $(2 \pm 0,1) \cdot 10^{4}$ & $(1,58 \pm 0,1) \cdot 10^{8}$ & 44,5 & 80 \\
\hline 400 & $(1 \pm 0,3) \cdot 10^{5}$ & $(2 \pm 0,2) \cdot 10^{8}$ & 50,5 & 82 \\
\hline 425 & $(7 \pm 0,2) \cdot 10^{5}$ & $(2,5 \pm 0,1) \cdot 10^{8}$ & 56,5 & 83,5 \\
\hline 450 & $(3 \pm 0,2) \cdot 10^{6}$ & $(3 \pm 0,1) \cdot 10^{8}$ & 62,5 & 85 \\
\hline 475 & $(6 \pm 0,1) \cdot 10^{6}$ & $(3 \pm 0,2) \cdot 10^{8}$ & 67,75 & 86,5 \\
\hline 500 & $(8 \pm 0,2) \cdot 10^{6}$ & $(3,1 \pm 0,1) \cdot 10^{8}$ & 73 & 88 \\
\hline 525 & $(8,5 \pm 0,3) \cdot 10^{6}$ & $(3,1 \pm 0,2) \cdot 10^{8}$ & 77,5 & 88,5 \\
\hline 550 & $(9 \pm 0,1) \cdot 10^{6}$ & $(3,1 \pm 0,1) \cdot 10^{8}$ & 81 & 89 \\
\hline
\end{tabular}

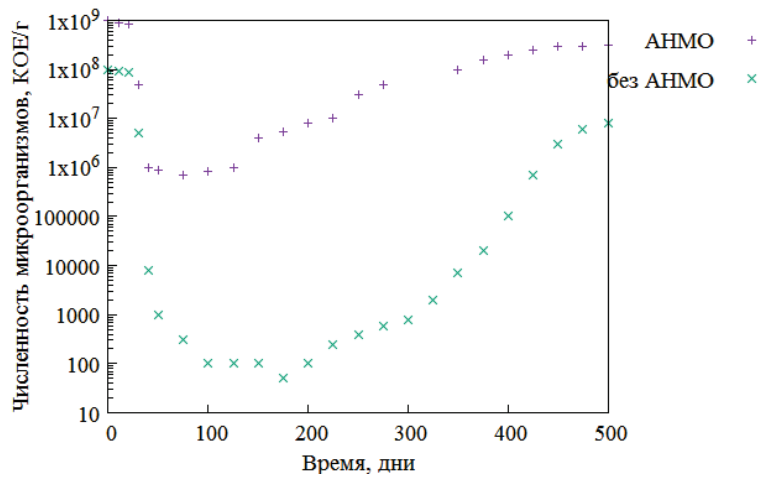

Pис. 1. Количество органотрофных микроорганизмов

Fig. 1. Number of organotrophic microorganisms 


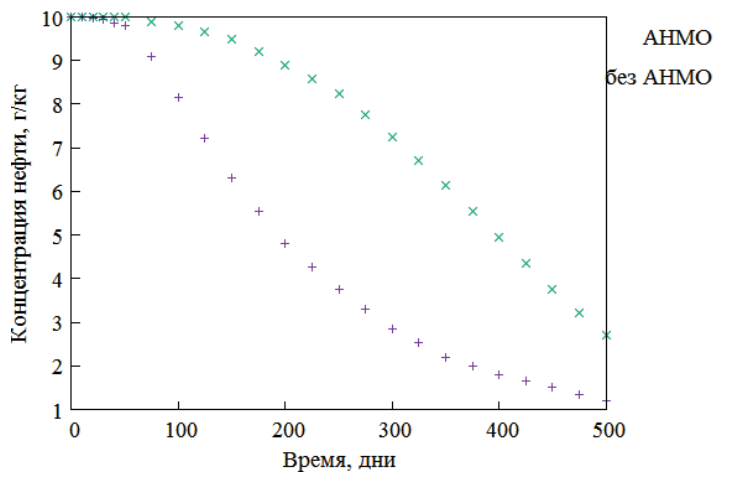

Pис. 2. Результаты процесса биодеструкции нефти АНМ

Fig. 2. Results of oil biodegradation by APM

\section{Построение модели процесса биотрансформации нефти микробными клетками}

Следующим шагом было моделирование процесса биотрансформации нефти на основе полученных экспериментальных данных. Построение математической модели производили для двух показателей: динамика изменения количества органотрофных микроорганизмов и биодеградация (убыль) нефтепродуктов.

Математическому моделированию и регулированию процессов биотрансформации нефти и других органических веществ в почве посвящены многочисленные публикации, в которых описываются математические модели изменения количества микробных клеток и биотрансформации нефти в почве [12, 18-21]. Достаточно полный обзор точечных моделей биологического разложения нефти приведен в [12], распределенные математические модели рассматривались в [21]. В работе [22] проанализированы труды в зарубежных изданиях по математическому моделированию биотрансформации органических поллютантов в почве.

Динамика численности микробных клеток в грунтах, загрязненных нефтепродуктами, включает 5 этапов: массовая гибель, адаптация, линейный и экспоненциальный прирост, стабилизация. Во многих случаях длительность этапов определяется видом присутствующих микроорганизмов, уровнем загрязнения и химическими свойствами нефти. При невысоких концентрациях нефти первой стадии может и не быть, а этап адаптации в действительности вовсе не соответствует показателям микробиологической активности незагрязненной почвы. На протяжении значительного времени наблюдается выравнивание данных показателей. Процессы диффузии влияют как на содержание нефтепродуктов в грунте, так и на микробиологическую активность почвы - хемотаксис. Математические модели хемотаксиса изучались во многих работах, а в последующем получили название моделей Келлера-Сигала. В частности, в статье [23] была разработана математическая модель биотрансформации нефти в ризосфере растений с использованием диффузии.
При создании математической модели количества микроорганизмов и биодеградации нефти была рассмотрена модифицированная модель из [12], которая учитывала также процессы диффузии нефтепродуктов и хемотаксис микроорганизмов (1):

$$
\begin{aligned}
& {\left[\begin{array}{l}
\frac{\partial M(t, x)}{\partial t}= \\
=M(t, x)\left[\begin{array}{l}
\frac{M_{0}-k M(t, x)}{K_{M}+M(t, x)} \times \\
\times\left(\alpha-\beta \frac{C(t, x)}{K_{C}+C(t, x)}\right)
\end{array}\right]+k_{1} \frac{\partial^{2} M}{\partial x^{2}} ;
\end{array}\right.} \\
& \frac{\partial Y(t, x)}{\partial t}= \\
& =\frac{Y(t, x)}{Y(t, x)+K_{Y Y}}\left(\begin{array}{l}
v C(t, x)- \\
-\eta \frac{Y(t, x)}{Y(t, x)+K_{Y Y}}
\end{array}\right)+k_{2} \frac{\partial^{2} Y(t, x)}{\partial x^{2}} ; \\
& \frac{\partial C(t, x)}{\partial t}= \\
& =-C(t, x)\left[\begin{array}{l}
\mu_{C} \frac{C(t, x)}{K_{S C}+C(t, x)} \times \\
\times \frac{Y(t, x)}{K_{M M}+Y(t, x)}
\end{array}\right]+\delta \frac{\partial^{2} C(t, x)}{\partial x^{2}},
\end{aligned}
$$

где $M(t)$ - численность микроорганизмов; $Y(t)-$ численность AHM; $C(t)$ - количество оставшихся в почве нефтепродуктов в момент времени $t ; t$ - время, в днях.

В модели основными составляющими кинетики нефти и микроорганизмов в почве взята кинетика Моно. Причины этого связаны с тем, что микроорганизмы вступают во взаимодействие после адсорбирования их на почвенные частицы. Как известно, процессы адсорбции-десорбции в почве хорошо описываются уравнением Ленгмюра [24] (2):

$$
q=\frac{q_{\max } \frac{k_{a}}{k_{d}}}{1+\frac{k_{a}}{k_{d}}},
$$

где $q$ - количество адсорбированного вещества (микроорганизмов); $k_{a}, k_{d}$ - константы скорости адсорбции и десорбции.

Значение коэффициентов в модели (1) подбирались методом вариации:

$$
\begin{gathered}
k=0,9, \alpha=10, \beta=10000, \\
K_{M}=10^{9}, K_{C}=50, k_{1}=0,1, \\
v=30, \eta=50, K_{Y Y}=2 \cdot 10^{8}, k_{2}=-0,1, \\
\lambda_{\tilde{N}}=40, K_{S C}=1, K_{M M}=10^{7}, \delta=0,1, \mu_{C}=10 .
\end{gathered}
$$

Система уравнений решалась численно, для чего была написана программа на языке Python. Численное решение осуществлялось методом предиктор-корректор. 
Системы предиктор-корректор - совокупность способов, принадлежащих к типу алгоритмов, созданных для интегрирования обыкновенных дифференциальных уравнений (ОДУ). Данные методы состоят из двух этапов:

- На первом этапе (предиктор) определяется некоторая функция от значений, рассчитанных на предшествующем этапе, чтобы получить аппроксимированное значение искомой функции в последующей точке.

- На следующем этапе (корректор) корректируется найденное предварительное значение с использованием спрогнозированного значения функции и другого оператора, чтобы провести интерполяцию значения искомой функции в той же самой точке.

Таким образом, очевидно, что начальный этап осуществляется путем явных методов, а последующий предполагает использование формул неявных методов, где справа вместо неопределенной величины $u(n+1)$ ставится результат предсказания $u(n+1 / 2)$. Применение данного метода для нахождения решений дифференциальных уравнений обеспечивает достаточную точность вычислений и отсутствие показателя самостартуемости (т. е. для начала расчетов по методу предиктор-корректор необходимо изначально использовать другой самостартующий способ).

Проведенные вычисления показали достаточно высокую сходимость расчетных значений с экспериментальными (рис. 3,4$)$.

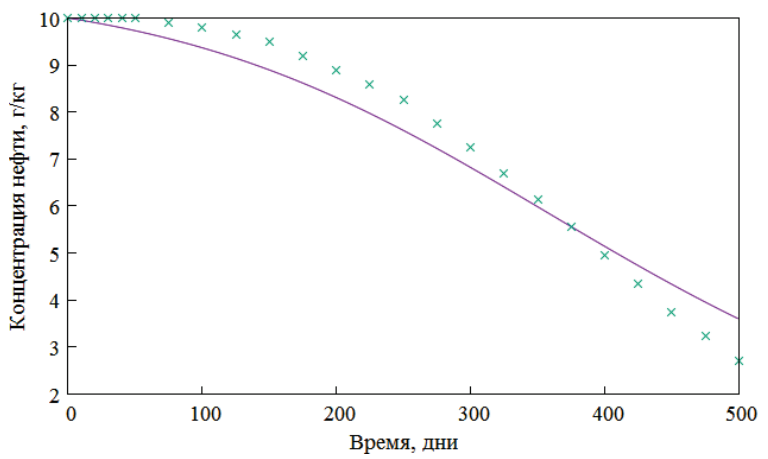

Рис. 3. Концентрация нефти (без АНМО)

Fig. 3. Oil concentration (without APM)

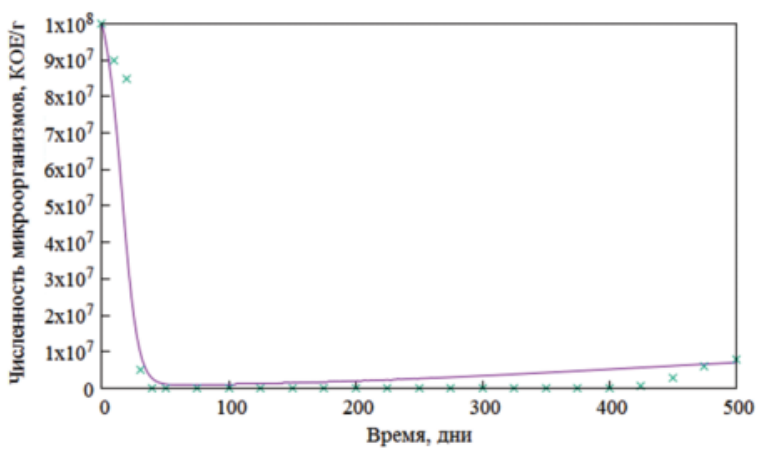

Pис. 4. Численность микроорганизмов (без АНМО)

Fig. 4. Number of microorganisms (without APM)
При создании математической модели изменения количества микроорганизмов и динамики биодеградации нефти с добавлением AНМ в модель (1) была добавлена функция $S(t)$, которая учитывает добавление в почву AНМ в начальный момент времени (3):

$$
\begin{aligned}
& \int \frac{\partial M(t, x)}{\partial t}= \\
& M(t, x)\left[\begin{array}{c}
\frac{S(t)+M_{0}-k M(t, x)}{K_{M}+M(t, x)} \times \\
\times\left(\alpha-\beta \frac{C(t, x)}{K_{C}+C(t, x)}\right)
\end{array}\right]+k_{1} \frac{\partial^{2} M}{\partial x^{2}} ; \\
& \frac{\partial Y(t, x)}{\partial t}= \\
& \left\{=\frac{Y(t, x)}{Y(t, x)+K_{Y Y}}\left(\begin{array}{l}
v C(t, x)+S(t)- \\
-\eta \frac{Y(t, x)}{Y(t, x)+K_{Y Y}}
\end{array}\right)+k_{2} \frac{\partial^{2} Y(t, x)}{\partial x^{2}} ;\right. \\
& \frac{\partial C(t, x)}{\partial t}= \\
& =-C(t, x)\left[\begin{array}{l}
\mu_{C} \frac{C(t, x)}{K_{S C}+C(t, x)} \times \\
\times \frac{Y(t, x)}{K_{M M}+Y(t, x)}
\end{array}\right]+\delta \frac{\partial^{2} C(t, x)}{\partial x^{2}} ; \\
& S(t)=\alpha_{S} e^{-t^{4}},
\end{aligned}
$$

где $M(t)$ - численность микроорганизмов; $Y(t)$ численность AHМ; $C(t)$ - количество оставшихся в почве нефтепродуктов в момент времени $t ; S(t)-$ функция, определяющая количество AHM, внесенных в почву; $t$ - время, в днях.

Данная система уравнений также решалась с применением метода предиктора-корректора. Коэффициенты для данной модели получились следующими:

$$
\begin{gathered}
k=0,9, \alpha=5, \beta=5000, \\
K_{M}=5 \cdot 10^{9}, K_{C}=50, k_{1}=0.1 ; \\
v=150, \eta=80, K_{Y Y}=2 \cdot 10^{8}, k_{2}=-0,1 ; \\
\lambda_{\mathrm{C}}=250, K_{S C}=6, K_{M M}=9 \cdot 10^{6}, \delta=-0,1, \mu_{C}=20 ; \\
\alpha_{S}=100 .
\end{gathered}
$$

Сравнение полученных коэффициентов с коэффициентами математической модели (1) показывает их несущественное изменение. В то же время можно отметить, что повышение общей численности микроорганизмов из-за внесенной ассоциации и увеличение численности нефтедеструктирующих микроорганизмов приводит к росту коэффициентов, отвечающих за интенсивность биотрансформации нефти. В первую очередь эта скорость возрастает в связи с увеличением числа микробных клеток, подвергающих биотрансформации нефть и продукты ее распада. Полученные результаты хорошо согласовывались с экспериментальными данными (рис. 5, 6). 


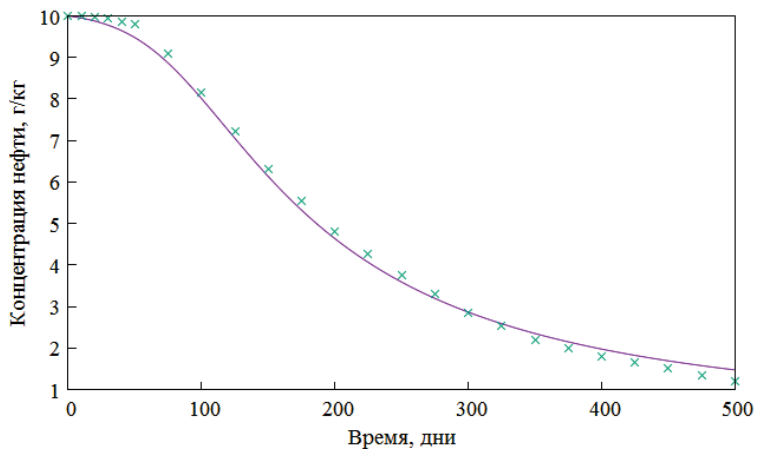

Pис. 5. Концентрация нефти (с АНМО)

Fig. 5. Oil concentration (with APM)

\section{Заключение}

Таким образом, полученная модель адекватно описывает процессы, происходящие в нефтезагрязненном грунте, в частности интенсивность изменения количества микробных клеток, а также уменьшение концентрации нефтепродуктов во

\section{СПИСОК ЛИТЕРАТУРЫ}

1. Повышение эффективности рекультивации нефтезагрязненных грунтов / Г.Г. Ягафарова, Л.Р. Акчурина, Ю.А. Федорова, И.Р. Ягафаров, А.Х. Сафаров // Башкирский химический журнал. - 2011. - Т. 18. - № 2. - С. 72-74.

2. Коршунова Т.Ю., Четвериков С.П., Логинов 0.Н. Перспективы использования консорциума углеводородокисляющих микроорганизмов для очистки нефтезагрязнённой почвы крайнего севера // Теоретическая и прикладная экология. - 2016. № 1. - C. 88-94.

3. Биогенное окисление высоковязкой нефти ашальчинского месторождения и ее гетероорганических соединений / Д.А. Филатов, Е.Б., Кривцов Н.Н. Свириденко, А.К. Головко, Л.К. Алтунина // Нефтехимия. - 2017. - Т. 57. - № 4. - С. 386-393.

4. Алтунина Л.К., Сваровская Л.И. Микробиологический метод глубокой очистки нефтешлама, загрязненного вязкой нефтью месторождения Цаган-Элс (Монголия) // Нефть. Газ. Новации. - 2016. - № 6. - С. 50-54.

5. Wicke D., Böckelmann U., Reemtsma T. Environmental influences on the partitioning and diffusion of hydrophobic organic contaminants in microbial biofilms // Environmental science and technology. - 2008. - V. 42. - № 6. - P. 1990-1996.

6. Биоремедиация грунтов, загрязненных тяжелой нефтью / Г.Г. Ягафарова, А.К. Мазитова, С.В. Леонтьева, А.Х. Сафаров, Д.Р. Вахитова // SOCAR Proceedings. - 2016. - № 3. C. $75-80$.

7. Seng P. Handbook of microbiological soil remediation. - Karlsruhe: Landesanstaltt fuer Umweltschutz Baden-Wuertenberg und Forschungzentrum, 1991. - $131 \mathrm{p}$

8. Biodegradation pattern of hydrocarbons from a fuel oil-type complex residue by an emulsifier-producing microbial consortium / M. Nievas, M. Commendatore, J. Esteves, V. Bucala // Journal of Hazardous Materials. - 2008. - V. 154. - № 1-3. - P. 96-104.

9. Biodegradation of petroleum hydrocarbon vapors: laboratory studies on rates and kinetics in unsaturated alluvial sand / P. Hohener, P. Duwig, G. Pasteris, K. Kaufmann, N. Dakhel, H. Harms // Journal of Contaminant Hydrology. - 2003. - V. 66. - № 1-2. P. 93-115.

10. Biodegradation of organic chemicals in soil/water microcosms system: Model development / L. Liu, J.A. Tindall, M.J. Friedel,

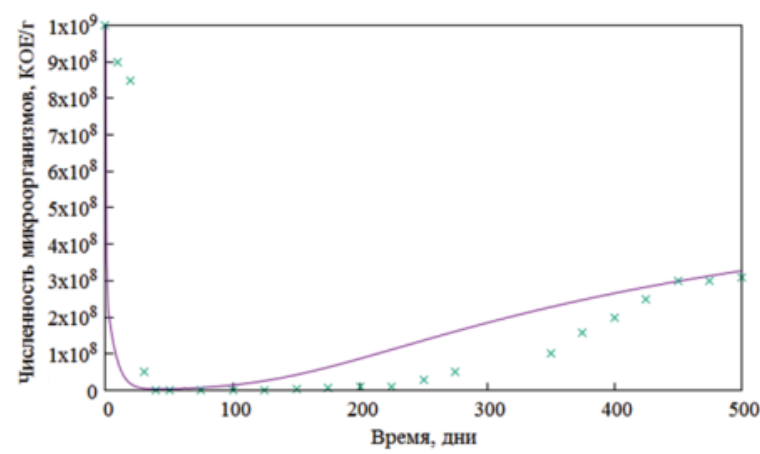

Puс. 6. Численность микроорганизмов (с АНМО)

Fig. 6. Number of microorganisms (with APM)

времени. Данные, полученные в результате прогнозирования системы почва-нефть-микроорганизмы, позволят повысить эффективность очистки нефтезагрязненного грунта и тем самым оздоровить окружающую природную среду.

W. Zhang // Water, Air, and Soil Pollution. - 2007. - V. 178. № 1-4. - P. 131-143.

11. Lee E., Banks M.K. Bioremediation of petroleum contaminated soil using vegetation: a microbial study // Journal of Environmental Science and Health. Part A. - 1993. - V. 28. - № 10. P. 2187-2198.

12. Водопьянов В.В., Гузаиров М.Б., Киреева Н.А. Математическое моделирование процессов в антропогенно нарушенных почвенных биосистемах. - М.: Машиностроение, 2010. - 232 с.

13. Prommer H., Barry D., Davis G. Modelling of physical and reactive processes during biodegradation of a hydrocarbon plume under transient groundwater flow conditions // Journal of Contaminant Hydrology. - 2002. - V. 59. - № 1-2. - P. 113-131.

14. Ефремов Г.И. Моделирование химико-технологических процессов. - М.: ИНФРА-М, 2017. -255 с.

15. Иванов В.И. Математические методы в биологии. - Кемерово: Изд-во КемГУ, 2012. - 196 с.

16. Природоохранный нормативный документ федерального уровня 16.1:2.2.22-98. Методика выполнения измерений массовой доли нефтепродуктов в минеральных, органогенных, органоминеральных почвах и донных отложениях методом ИК-спектрометрии. - СПб.: Акционерное общество закрытого типа «Спектр-М», 1998. - 12 с.

17. Герхардт Ф. Методы общей бактериологии. В 3-х томах. - М.: Мир, 1983. - 536 c.

18. Моделирование динамики органического вещества почв / А.В. Смагин, Н.Б. Садовникова, М.В. Смагина и др. - М.: Изд-во Московского государственного университета, 2001. $120 \mathrm{c.}$

19. El-Kadi A. Modeling hydrocarbon biodegradation in tidal aquifers with water-saturation and heat inhibition effects // Journal of Contaminant Hydrology. - 2001. - V. 51. - № 1-2. P. 97-125.

20. Wanner 0., Reichert P. Mathematical modelling of mixedculture biofilms // Biotechnol. Bioeng. - 1996. - V. 49. - № 2. P. $172-184$.

21. Росновский И.Н. Системный анализ и математическое моделирование процессов в почвах. - Томск: Томский государственный университет, 2007. -312 с.

22. Поташев К.А., Малов П.В., Бреус И.П. Учет биодеградации в математических моделях транспорта органических загрязни- 
телей в природных пористых средах. Обзор современной литературы // Ученые записки Казанского университета. - 2011. T. 153. - Кн. 3. - C. 144-170.

23. Водопьянов В.В., Водопьянова Л.Л. Математическое моделирование биодеградации нефти в ризосфере растений с использованием диффузии // Вестник Уфимского государственного авиационного университета. - 2014. - Т. 18. - № 4. C. $178-182$.
24. Decontamination of polyaromatic hydrocarbons from soil by steam stripping: mathematical modeling of the mass transfer and energy requirement / 0. Braass, C. Tiffert, J. Hohne et al. // Journal of Environmental Science and Technology. - 2003. V. 37. - № 21. - P. 5001-5007.

\section{Информация об авторах}

Сафаров A.X., кандидат технических наук, доцент кафедры прикладной экологии Уфимского государственного нефтяного технического университета.

Водопьянов B.B., доктор технических наук, профессор кафедры математики Уфимского государственного авиационногол технического университета.

Ягафарова Г.Г., доктор технических наук, профессор кафедры прикладной экологии Уфимского государственного нефтяного технического университета.

Дусаева Я.М., магистрант кафедры математики Уфимского государственного авиационного технического университета.

Акчурина Л.P., кандидат технических наук, доцент кафедры прикладной экологии Уфимского государственного нефтяного технического университета. 


\title{
PREDICTION OF HEAVY OIL BIODEGRADATION BY ASSOCIATION OF ABORIGINAL PETRODESTRUCTIVE MICROORGANISMS
}

\author{
Albert H. Safarov', \\ Alsaf1978@mail.ru \\ Vladimir V. Vodopyanov ${ }^{2}$ \\ Vodop@yandex.ru \\ Guzel G. Yagafarova', \\ Kafedra_ecologia@mail.ru \\ lana M. Dusaeva², \\ Yanadusaeva@mail.ru \\ Lilya R. Akchurina', \\ Akchurina_Ir@mail.ru \\ 1 Ufa State Petroleum Technological University, \\ 1, Kosmonavtov street, Ufa, 450044, Russia. \\ 2 Ufa State Aviation Technical University, \\ 12, Karl Marks street, Ufa, 450008, Russia.
}

The relevance of the research is caused by the need to monitor and predict changes in oil-contaminated soil, in particular, to intensify biodegradation of oil and oil products, as well as changes in the number of organotrophic microorganisms over time. The data, obtained from modeling in the system "soil-oil-microorganisms», will increase the efficiency of cleansing oil-contaminated soil and thereby improve the environment.

The aim of the research was to create a mathematical model reproducing heavy oil components degradation by association of indigenous petrodestructive microorganisms.

The object of the study is the heavy oil-contaminated soil of the Nizhne-Karmalskoe field, as well as the association of indigenous petrodestructive microorganisms.

Methods. The modified Keller-Segal model, which also takes into account the processes of diffusion of petroleum products and the hemotaxis of microorganisms, was used as a database for modeling. The system of equations was solved numerically, using a specially developed in the Python language program. The numerical solution was carried out using the predictor-corrector method.

Results. The work consisted of two stages - experiment and calculation. During the first stage of the work, the biodegradation of oil and petroleum products was studied by a consortium of indigenous oil destructive microorganisms. On the basis of the obtained results, the experimental data base was established. At the second stage, according to the previously obtained data, the authors constructed a mathematical model describing heavy oil biodegradation and changes in the number of oil-destructing microorganisms in oil-contaminated soil. The calculations showed great consistency of estimated data with experimental ones. The obtained model would predict measures for environmental friendly methods of cleaning oil-contaminated soils at the early stages of cleaning.

Key words:

Heavy oil, biodegradation, oil-contaminated soils, aboriginal petrodestructive microorganisms, mathematical model.

\section{REFERENCES}

1. Yagafarova G.G., Akchurina L.R., Fedorova Y.A., Yagafarov I.R., Safarov A.H. Improvement of the efficiency of oil-contaminated soil recultivation. Bashkir chemical journal, 2011, vol. 18, no. 2, pp. 72-74. In Rus.

2. Korshunova T.Y., Chetverikov S.P., Loginov 0.N. Prospects for the use of a consortium of hydrocarbon-oxidizing microorganisms for the purification of oil-contaminated soil of the far North. Theoretical and applied ecology, 2016, no. 1, pp. 88-94. In Rus.

3. Filatov D.A., Krivtsov E.B., Sviridenko N.N., Golovko A.K., Altunina L.K. Biogennoe okislenie vysokovyazkoy nefti ashalchinskogo mestorozhdeniya i ee geteroorganicheskikh soedineniy [Biogenic oxidation of high-viscosity oil of Ashalchinskoye field and its heteroorganic compounds]. Neftekhimiya, 2017, vol. 57, no. 4 , pp. 386-393.

4. Altunina L.K., Svarovskaya L.I. Mikrobiologicheskiy metod glubokoy ochistki nefteshlama, zagryaznennogo vyazkoy neftyu mestorozhdeniya Cagan-Els (Mongoliya) [Microbiological method of deep purification of oil sludge-contaminated viscous oil deposits of Tsagan-ELS (Mongolia)]. Neft. Gaz. Novacii, 2016, no. 6, pp. $50-54$.

5. Wicke D., Böckelmann U., Reemtsma T. Environmental influences on the partitioning and diffusion of hydrophobic organic contaminants in microbial biofilms. Environmental science and technology, 2008, vol. 42, no. 6, pp. 1990-1996.

6. Yagafarova G.G., Mazitova A.K., Leonteva S.V., Safarov A.H., Vakhitova D.R. Bioremediation of heavy oil-contaminated soils. SOCAR Proceedings, 2016, no. 3, pp. 75-80. In Rus.

7. Seng P. Handbook of microbiological soil remediation. Karlsruhe, Landesanstaltt fuer Umweltschutz Baden-Wuertenberg und Forschungzentrum, 1991. $131 \mathrm{p}$.

8. Nievas M., Commendatore M., Esteves J., Bucala V. Biodegradation pattern of hydrocarbons from a fuel oil-type complex residue by an emulsifier-producing microbial consortium. Journal of $\mathrm{Ha}$ zardous Materials, 2008, vol. 154, no. 1-3, pp. 96-104. 
9. Hohener P., Duwig P., Pasteris G., Kaufmann K., Dakhel N., Harms H. Biodegradation of petroleum hydrocarbon vapors: laboratory studies on rates and kinetics in unsaturated alluvial sand. Journal of Contaminant Hydrology, 2003, vol. 66, no. 1-2, pp. $93-115$.

10. Liu L., Tindall J.A., Friedel M.J., Zhang W. Biodegradation of organic chemicals in soil/water microcosms system: model development. Water, Air, and Soil Pollution, 2007, vol. 178, no. 1-4, pp. 131-143.

11. Lee E., Banks M.K. Bioremediation of petroleum contaminated soil using vegetation: a microbial study. Journal of Environmental Science and Health. Part A, 1993, vol. 28, no. $10 \mathrm{~m}$ pp. 2187-2198.

12. Vodopyanov V.V., Guzairov M.B., Kireeva N.A. Matematicheskoe modelirovanie protsessov $v$ antropogenno narushennykh pochvennykh biosistemakh [Mathematical modeling of processes in anthropogenically disturbed soil biosystems]. Moscow, Mashinostroenie Publ., 2010. 232 p.

13. Prommer H., Barry D., Davis G. Modelling of physical and reactive processes during biodegradation of a hydrocarbon plume under transient groundwater flow conditions. Journal of Contaminant Hydrology, 2002, vol. 59, no. 1-2, pp. 113-131.

14. Efremov G.I. Modelirovanie khimiko-tekhnologicheskikh protsessov [Modeling of chemical technology processes]. Moscow, INFRA-M Publ., 2017. 255 p.

15. Ivanov V.I. Matematicheskie metody v biologii [Mathematical methods in biology]. Kemerovo, Kemerovo state University Publ., 2012. $196 \mathrm{p}$.

16. Prirodookhranny normativny dokument federalnogo urounya 16.1:2.2.22-98. Metodika vypolneniya izmereny massovoy doli nefteproduktov $v$ mineralnykh, organogennykh, organomineral nykh pochvakh i donnykh otlozheniyakh metodom IK-spektrometrii [Federal level environmental regulation] 16.1: 2.2.22-98. Methodologies for measuring procedures of mass fraction of oil products in mineral, organogenic, organomineral soils and sedi- ments by the method of IR-spectrometry. St-Petersburg, Spectrum-M closed joint-stock company Publ., 1998. 12 p.

17. Gerhardt F. Metody obshchey bakteriologii [Methods of general bacteriology]. Moscow, Mir Publ., 1983. 536 p.

18. Smagin A.V., Sadovnikova M.V., Smagina M.V. Modelirovanie dinamiki organicheskogo veshchestva pochv [Modeling the dynamics of soil organic matter]. Moscow, Moscow State University Publ., 2001. 120 p.

19. El-Kadi A. Modeling hydrocarbon biodegradation in tidal aquifers with water-saturation and heat inhibition effects. Journal of Contaminant Hydrology, 2001, vol. 51, no. 1-2, pp. 97-125.

20. Wanner 0., Reichert P. Mathematical modelling of mixedculture biofilms. Biotechnol. Bioeng, 1996, vol. 49, no. 2, pp. 172-184.

21. Rosnovsky I.N. Sistemny analiz i matematicheskoe modelirovanie protsessov v pochvakh [System analysis and mathematical modeling of processes in soils]. Tomsk, Tomsk State University Publ., 2007. 312 p.

22. Potashev K.A., Malov P.V., Breus I.P. Uchet biodegradatsii v matematicheskikh modelyakh transporta organicheskikh zagryazniteley v prirodnykh poristykh sredakh. Obzor sovremennoy literatury [Accounting of biodegradation in mathematical models of transport of organic pollutants in natural porous media. A review of the contemporary literature]. Uchenye zapiski Kazanskogo universiteta, 2011, vol. 153, no. 3, pp. 144-170.

23. Vodopyanov V.V., Vodopyanova L.L. Mathematical modeling of oil biodegradation in the rhizosphere of plants using diffusion. Bulletin of Ufa State Aviation University, 2014, vol. 18, no. 4, pp. 178-182. In Rus.

24. Braass 0., Tiffert C., Hohne J. Decontamination of polyaromatic hydrocarbons from soil by steam stripping: mathematical modeling of the mass transfer and energy requirement. Journal of Environmental Science and Technology, 2003, vol. 37, no. 21, pp. 5001-5007.

Received: 11 February 2019.

\section{Information about the authors}

Albert H. Safarov, Cand. Sc., associate professor, Ufa State Petroleum Technological University.

Vladimir V. Vodopyanov, Dr. Sc., professor, Ufa State Aviation Technical University.

Guzel G. Yagafarova, Dr. Sc., professor, Ufa State Petroleum Technological University.

Iana M. Dusaeva, graduate student, Ufa State Aviation Technical University.

Lilya R. Akchurina, Cand. Sc., associate professor, Ufa State Petroleum Technological University. 